\title{
Hepatic hydatid cyst: a non-surgical approach
}

\author{
Pedro Silva Vaz ${ }^{[1]}$, Eduardo Pereira ${ }^{[2]}$, Sergiu Usurelu ${ }^{[1]}$, Ana Monteiro ${ }^{[1]}$, Ana Caldeira ${ }^{[2]}$, \\ Gina Melo ${ }^{[1]}$, Rui Sousa ${ }^{[2]}$, António Gouveia ${ }^{[1]}$ and Arnandina Loureiro ${ }^{[1]}$
}

[1]. Serviço de Cirurgia Geral, Hospital Amato Lusitano, Unidade Local de Saúde de Castelo Branco, Castelo Branco, Portugal. [2]. Serviço de Gastroenterologia, Hospital Amato Lusitano, Unidade Local de Saúde de Castelo Branco, Castelo Branco, Portugal.

\section{ABSTRACT}

Echinococcosis/hydatidosis is common in societies where agriculture and livestock are frequent, and represents a public health problem. The therapeutic management depends on the cyst's characteristics, the patient, and surgical contraindications. Endoscopic retrograde cholangiopancreatography is a valuable tool in the diagnosis and treatment of complicated hepatic hydatid disease. Ultrasonography is a useful diagnostic, therapeutic and follow-up tool. The authors report a case of a 56 years old patient who was diagnosed with a hepatic hydatid cyst in the IVa/VIII segments, describe the therapeutic options and 50 months of disease-free follow-up.

Keywords: Hepatic hydatid cyst. Endoscopic retrograde cholangiopancreatography. Ultrasonography.

\section{INTRODUCTION}

Echinococcosis/hydatidosis is common in societies where agriculture and livestock are frequent, and it continues to represent a serious public health problem, especially in the Mediterranean, Middle East, South America, New Zeland and Turkey ${ }^{1-5}$. In Portugal, Cartucho et al. point to a higher incidence in Alentejo, Setúbal, Vale do Tejo, and Castelo Branco ${ }^{6}$.

Hydatid cysts are most often hepatic (50-80\%) and pulmonary (5-30\%) but they may also be found in other locations ${ }^{1-4,7}$. Treatment depends on the cystic lesion's characteristics, the patient, and whether there are any contraindications to surgery, which is still the therapeutic gold-standard ${ }^{5,8}$. Medical treatment is characterized by the use of benzimidazoles ${ }^{1,7}$. Puncture, aspiration, injection and re-aspiration (PAIR) has been shown to be effective in the presence of non-complicated hydatid cysts. Endoscopic retrograde cholangiopancreatography (ERCP) has been described as the best approach in complicated hepatic hydatid disease, being both a diagnostic and therapeutic tool ${ }^{2}$.

\section{CASE REPORT}

A 56 year old female patient, born and residing in the City of Castelo Branco, Portugal, underwent abdominal ultrasonography in the clinical context of recently diagnosed diabetes mellitus associated with dyspeptic complaints. The ultrasonography showed a predominantly liquid heterogeneous formation of about $75 \mathrm{~mm}$, apparently capsulated, located in the IVa/VIII segments of the liver, with characteristics which suggested a hydatid cyst. Abdominopelvic computerized tomography (CT) revealed a $80 \times 62 \times 42 \mathrm{~mm}$ cystic formation, adjacent the gallbladder, with incipient wall calcification

Address to: Dr. Pedro Silva Vaz. Serviço de Cirurgia Geral/Hospital Amato Lusitano/Unidade Local de Saúde de Castelo Branco. Av. Pedro Álvares Cabral, 6000-085 Castelo Branco, Portugal.

Phone: 00351966498337

e-mail: pedro.silvavaz@gmail.com

Received in 19/10/2011

Accepted in 27/01/2012 and roughly nodular endoluminal images. It extended until the VIII segment in strict association with the inferior vena cava (IVC) (Figure 1). Serology tests for hydatidosis were positive. Endoscopic retrograde cholangiopancreatography showed a contrast filled collection, which proved a communication between the cyst and the biliary tree. However, it was not possible to determine the fistulous trajectory. Therapy with albendazole $(15 \mathrm{mg} / \mathrm{kg} /$ day) was initiated. The following therapeutic options were proposed in this clinical context: surgical intervention in a specialist hepatic surgery center, due to the location of the cystic lesion as well as the proximity to the vascular structures, such as the IVC, or non-surgical treatment in our

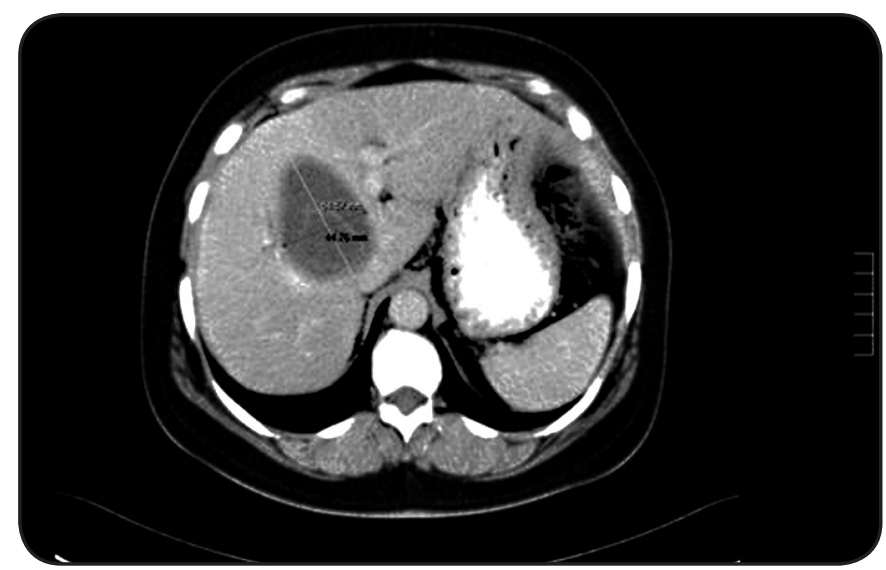

FIGURE 1 - Abdomino-pelvic computerized tomograph revealing a cystic formation with incipient wall calcification and roughly nodular endoluminal images.

institution with the support of the Gastroenterology Department. Aware of the risks involved with the surgical option, the patient chose the non-surgical treatment. After 6 months of treatment, an elevation of the hepatic enzymology and cholestasis was verified. This was attributed to albendazole hepatotoxicity, and a decision was made to suspend medical treatment. At this point, imaging showed a significant reduction of the size of the lesion, and the serologic tests were negative. The patient abandoned the follow-up in light of the clinical improvement.

Sixteen months after previous admission, she was admitted to the Surgical Department for cholangitis. Abdominal ultrasonography 
revealed a $60 \times 40 \mathrm{~mm}$ hydatid cyst located between the hepatic hilus IVC, with no alterations of the gallbladder and with slight dilation and wall thickening of the common bile duct (CBD). Serology was again positive and therefore albendazole $(10 \mathrm{mg} / \mathrm{kg} /$ day) was initiated. She performed ERCP (Figure 2) which showed contrast-filled cyst with easy cannula access. A basket was used to clean the biliary duct and there was evidence of the removal of hydatids. At the end of the procedure, a double pig's tail tube was placed in the cyst (Figure 3). The patient was again given a choice of therapeutic options and still refused surgical treatment. Ten days later, she performed another ERCP to replace the double pig's tail tube by a nasocystic catheter. Three lavages with $20 \%$ hypertonic solution were carried out over the following 5 days until the liquid drained from the catheter was clear. Irrigation was done under clinical and ultrasonographic control which allowed the direct visualization of the cystic cavity filling. The nasocystic catheter was removed after the third cyst lavage.

Five months later she presented elevated liver function tests again. Ultrasonography showed a residual cyst. The serology study was repeated and was negative. The albendazole was therefore suspended after one month of serologic evaluation.

Currently the patient is under annual ultrasonographic control. The last appointment, at 50 months, showed a residual cyst. The patient is asymptomatic and liver function tests are normal.

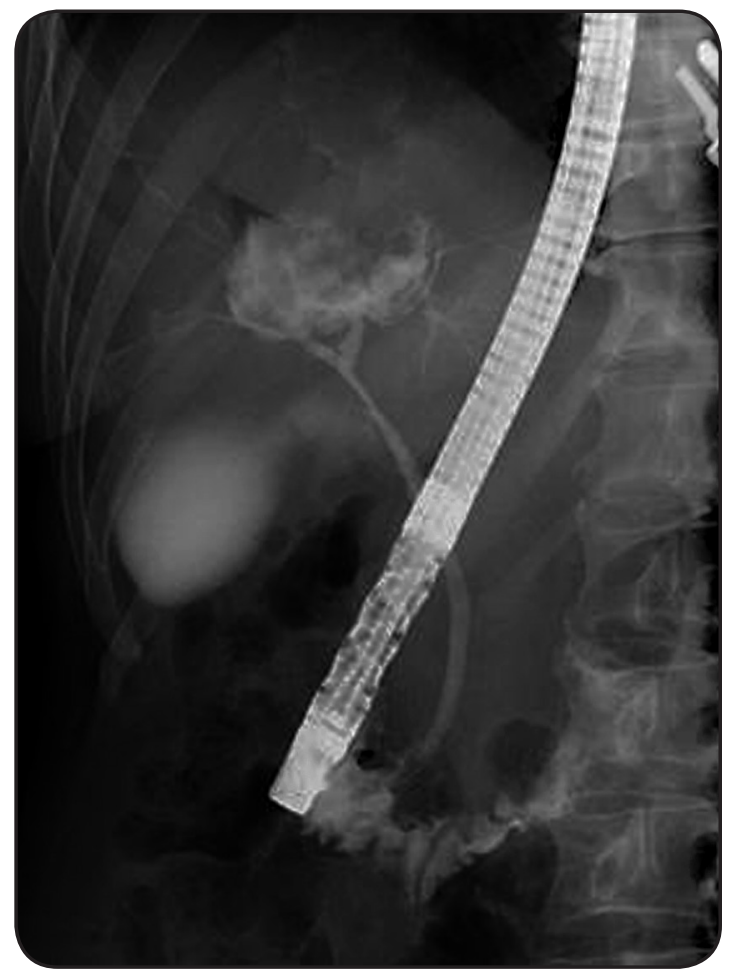

FIGURE 2 - Endoscopic retrograde cholangiopancreatography showing contrast cyst formation with easy cannula access.

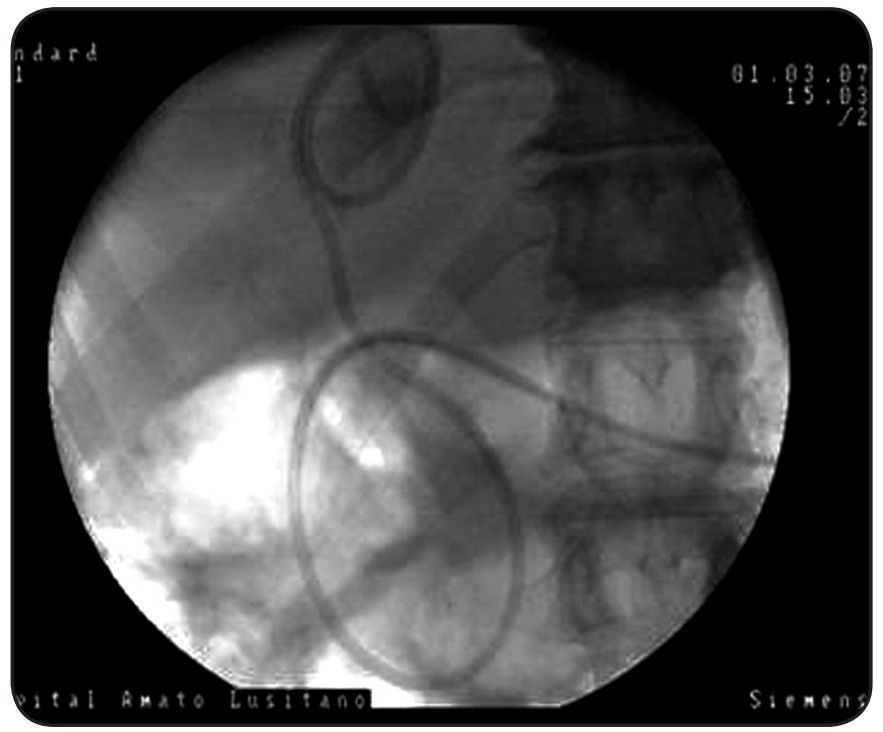

FIGURE 3 - Double pig's tail tube in the cyst formation for draining.

\section{DISCUSSION}

The indications for ERCP in hepatic hydatid cyst patients during the pre-surgical period include the characterization of the relation between the hydatid cyst and the biliary tree, which aid in the drawing up of a surgical plan, the evaluation of acute clinical conditions (cholangitis and obstruction of $\mathrm{CBD}$ ), the decrease of the incidence of post-surgical fistulas, or even the curative treatment of intrabiliary rupture cases if the cystic cavity or the biliary duct are accessible through this method.

In the presented clinical case, ERCP was used both for characterization of the biliary tree (diagnosis of intrabiliary rupture), and in the context of cholangitis for the placement of a nasocystic catheter for irrigation and draining (therapeutic).

The diagnosis of hepatic hydatidosis using imaging is based on the $\mathrm{CT}$, abdominal ultrasonography, both described as the ideal exams for diagnosis and for evaluation of therapeutic efficacy. CT and magnetic resonance imaging (MRI) provide additional structural details and show more precisely the location and depth of the cyst within the liver, data essential for planning treatment. According to Gharbi, ultrasonography is the preferred method for the classification of hydatid cysts ${ }^{1,3,7-12}$. In some cases, ultrasonography is pathognomonic, allowing the definition of the parasite's stage of evolution (WHO classification) $)^{3}$.

In the majority of publications, the therapeutic options for the hepatic hydatid disease include surgery and benzimidazoles.

Surgery is still the primary treatment option and promotes the inactivation of the scolex, the prevention of the dissemination of the cystic content into the peritoneal cavity, the elimination of all the cyst's viable elements, and the handling of the residual cavity. Nevertheless, the main surgical complications are postoperative biliary fistula (5-25\%) and relapse $(2-16 \%)^{1,2}$.

The use of ERCP both pre and post-operatively is indicated, and it may be used isolatedly as a therapeutic tool, as described in this clinical case. 
As a therapeutic method, ERCP was essential in the context of the patient's cholangitis, as well as in the treatment of the hydatid disease with placement of a nasocystic tube that allowed for the controlled draining of hydatids and irrigation with a scolicidal agent. Simsek et al state that endoscopic procedures, namely sphincterotomy (ETE), stent insertion or nasobiliary draining have a high success rate of approximately $90 \%$ in cystic hydatid disease 2 .

Therapy with ERCP for hepatic hydatid cysts has been described by some authors as a first choice procedure in selected patients.

The use of ultrasonography as a tool to control each lavage has also been described here. In this case, ultrasonography has assumed a fundamental role in therapeutics, allowing a direct visualization of the $20 \%$ hypertonic solution filling of the cystic cavity leading to a control of the possible side effects of the scolicide (sclerosing cholangitis and pancreatitis ${ }^{2}$ ). The control, both ultrasonographical and clinical, allowed us to define of the safe quantity of scolicidal agent to be injected at each lavage.

The use of the ultrasonography as an aid in the non-surgical treatment of hydatid cysts is innovative.

The patient remains under imaging and clinical follow-up, the last of which reveals a residual image of a cyst. The 50 month follow-up with no relapse indicates therapeutic success.

Endoscopic retrograde cholangiopancreatography with ETE offers an excellent option with immediate results both in diagnosis and in therapeutics of hepatic hydatid disease with intrabiliary rupture. It could be an alternative treatment to be considered for high surgical risk patients.

Ultrasonography, used in this innovative manner, proved a useful aid in the non-surgical treatment of a hydatid cyst by allowing the safe quantification of scolicidal agent to be injected, thereby decreasing the side effects with which these substances are associated.

\section{ABSTRACT IN PORTUGUESE}

\section{Cisto hidático hepático: abordagem não cirúrgica}

A equinococose/hidatidose é comum em sociedades onde predominam a agricultura e a criação de gado, sendo um problema de saúde pública. As várias opções terapêuticas dependem das caraterísticas do quisto, do doente e da eventual presença de contraindicações cirúrgicas. A colangiopancreatografia retrógrada endoscópica constitui uma válida ferramenta no diagnóstico e tratamento da doença hidática hepática complicada. A ecografia é um instrumento útil no diagnóstico, na terapêutica e seguimento. Os autores apresentam um caso de uma doente de 56 anos a quem foi diagnosticado um quisto hidático hepático nos segmentos IVa/VIII, descrevem as opções terapêuticas e o seguimento de 50 meses livres de doença.

Palavras-chaves: Cisto hidático hepático. Colangiopancreatografia retrógrada endoscópica. Ultrassonografia.

\section{REFERENCES}

1. Pawlowski ZS, Eckert J, Vuitton RW, Ammann PK, Craig PS, Dar KF, et al. Echinococcosis in humans: clinical aspects, diagnosis and treatment. In: Eckert J, Gemmell MA, Meslin FX, Pawlowski ZS, editors. WHO/OIE Manual on Echinococcosis in Humans and Animals: a Public Health Problem of Global Concern. Paris, France: World Health Organization; 2001. p. 20-62.

2. Simsek H, Ozaslan O, Sayek I, Savas C, Bbasoglu O, Soylu AR, et al. Hepatic hydatid disease: diagnostic and therapeutic ERCP. Gastrointest Endosc 2003; 58:384-389.

3. Menezes-da-Silva A, Caldeira J, Nunes JL. PAIR - Alternativa terapêutica do quisto hidático do fígado. J Port Gastrenterol 2001, 8:113-120.

4. Palacios-Ruíz JA, Ramirez-Solis ME, Moreno-Moller M, Cardenas-Mejia A, Gonzalez-Monroy LE, Diaz-Pizarro Jl, et al. Seguridad y eficacia de la solución salina hipertónica al $17.7 \%$ durante el tratamiento laparoscópico de un quiste hidático hepático. Assoc Mex Cirugía Endoscópica 2001; 2:206-210.

5. Brunicardi FC, Andersen DK, Billiar TR, Dunn DL, Hunter JG, Pollock RE. Liver. Sxwartz's Principles of Surgery. $8^{\text {th }}$ ed. New York, USA: McGraw-Hill; 2005.

6. Cartucho D, Marrão G, Vaiadas G, Rocha G, Santana A, Patrício J. Caracterização das estirpes de Quisto Hidático em Portugal: onde estamos nós? Rev Saúde Amato Lusitano 1999; 9:13-17.

7. María Luisa C, Lloeznaly O, Julio V, Noya B, Carmen Z. Quiste hidatídico hepático: a propósito de un caso. Rev Soc Venezolana Gastrenterol 2007; 6:206-209.

8. Moreno-González E, Meneu Diáz JC, Moreno Elola A. Echinococcal Cyst. In: Baker RJ, Fischer JE, editors. Mastery of Surgery. $5^{\text {th }}$ ed. Philadelphia: Lippincott Williams Wilkins Inc; 2007. p. 1043-1075.

9. Reddy DN. Endoscopic diagnosis and management of biliary parasitosis [Internet]. Up to Date online 2008; Available from: http://www.uptodate.com/contents/ endoscopic-diagnosis-and-management-of-biliary-parasitosis/.

10. Özaslan E. Therapeutic endoscopic retrograde cholangiopancreatography and related modalities have many roles in hepatobiliary hydatid disease. World J Gastroenterol 2006; 12:4930-4931.

11. Manouras A, Genetzakis M, Antonakis PT, Lagoudianakis E, Pattas M, Papadima A, et al. Endoscopic management of a relapsing hepatic hydatid cyst with intrabiliary rupture: A case report and review of the literature. Can J Gastroenterol 2007; 21:249-253.

12. Dandan IS, Soweid AM, Abiad F. Hydatid cyst. Drugs, Diseases \& Procedures 2008; [Cited 2011 January 11]. Available from: http://emedicine.medscape.com/ article/178648-overview/. 